Document downloaded from:

http://hdl.handle.net/10251/75203

This paper must be cited as:

Desantes Fernández, JM.; García Oliver, JM.; Pastor Enguídanos, JM.; Ramírez Hernández, JG. (2011). Influence of nozzle geometry on ignition and combustion for highspeed direct injection diesel engines under cold start conditions. Fuel. 90(11):3359-3368. doi:10.1016/j.fuel.2011.06.006.

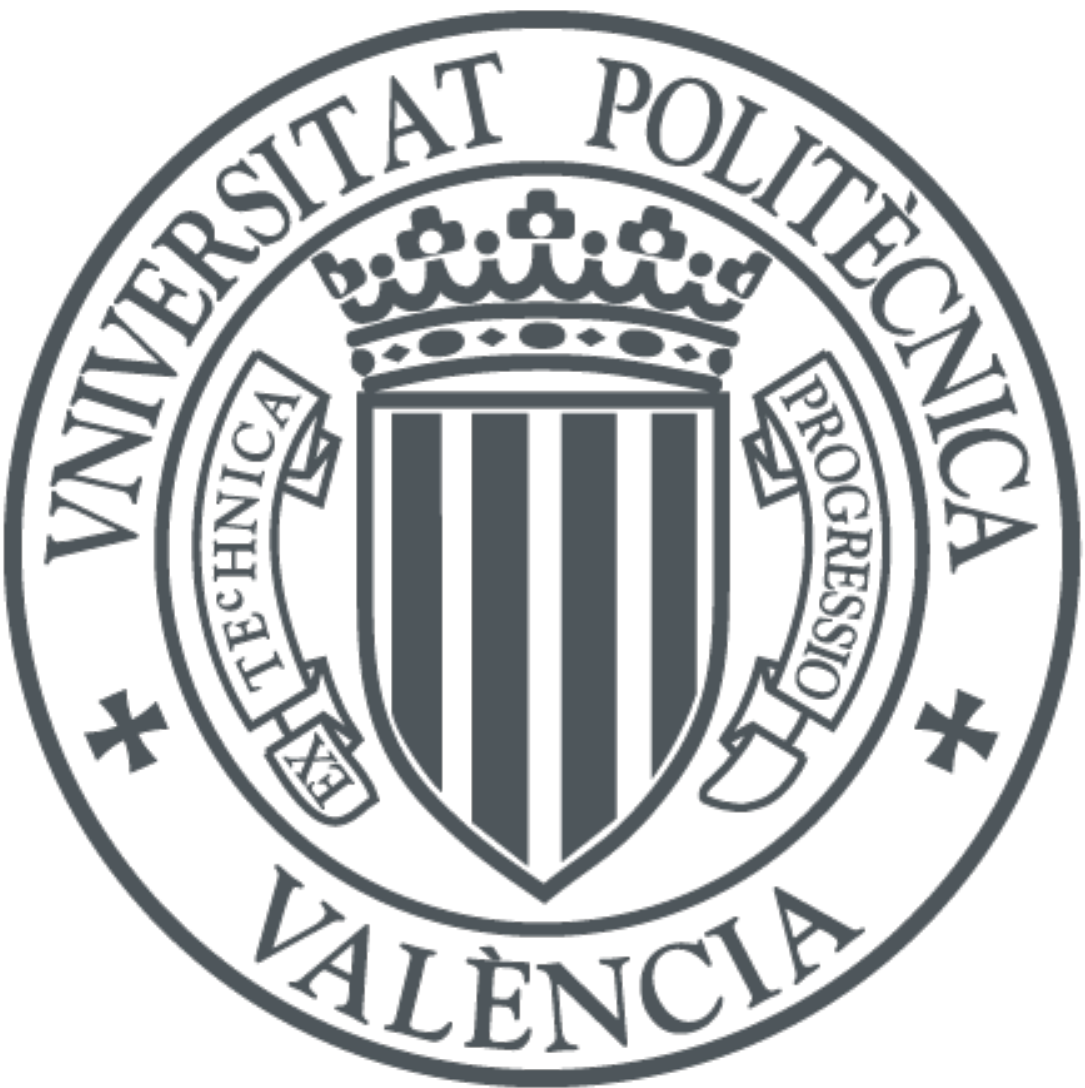

The final publication is available at

http://dx.doi.org/10.1016/j.fuel.2011.06.006

Copyright Elsevier

Additional Information 


\title{
Influence of nozzle geometry on ignition and combustion for high-speed direct injection diesel engines under cold start conditions
}

\author{
J.M. Desantes, J.M. García-Oliver*, J.M. Pastor, J.G. Ramírez-Hernández \\ CMT Motores Térmicos - Universidad Politécnica de Valencia \\ Camino Vera s/n - 46022 Valencia, Spain. \\ Telephone: +34 963877650, Fax: +34963877659
}

\begin{abstract}
Starting at low temperatures (below $0^{\circ} \mathrm{C}$ ) is an important issue for current and near future diesel engine technology. Low ambient temperature causes long cranking periods or complete misfiring in small diesel engines and, as a consequence, an increased amount of pollutant emissions. This paper is devoted to study the influence of nozzle geometry on ignition and combustion progression under glow-plug aided cold start conditions. This study has been carried out in an optically accessible engine adapted to reproduce in-cylinder conditions corresponding to those of a real engine during start at low ambient temperature. The cold start problem can be divided in two parts in which nozzle geometry has influence: ignition and main combustion progression. Ignition probability decreases if fuel injection velocity is increased or if the amount of injected mass per orifice is reduced, which is induced by nozzles with smaller hole diameter or higher orifice number, respectively. Combus-
\end{abstract}

\footnotetext{
*Corresponding author

Email address: jgarciao@mot.upv.es (J.M. García-Oliver )
} 
tion rates increase when using nozzles which induce a higher momentum, improving mixture conditions. For these reasons, the solution under these conditions necessarily involves a trade-off between ignition and combustion progression.

Keywords: Diesel combustion, Cold start, Injector nozzle, Ignition

[Table 1 about here.]

\section{Introduction}

In spite of all the improvements made in diesel technology to date, en3 gine starting is still a problem for current light-duty engines at low ambient 4 temperature and it is a limiting factor for future design trends. Depending 5 on ambient temperature, the starting process of a diesel passenger car engine 6 may result in long cranking periods with a large amount of pollutant emis7 sions $[1,2,3,4]$ or in the complete incapability of starting the engine. These 8 problems are caused by poor conditions for auto-ignition: relatively low peak compression temperature and pressure. Low peak compression temperature causes poor vaporization and increases chemical delays. Low peak compression pressure is a consequence of low intake pressure as well as high blow-by 12 level, as a consequence of low engine block temperature and low engine speed. As a reference to poor ignition conditions, Broatch et al [5] report that a light- 
facts evidence the necessity of improving knowledge about combustion under low temperature cold start conditions in order to overcome present and future limitations of diesel engines for passenger cars.

During the last decades most of the studies on low temperature cold start have been focused on trial-and-error procedures carried out in climatic chambers $[11,12,13,14]$. These studies have delivered valuable information, but several measurement uncertainties and the inability of using extra diagnostic tools have prevented from making a detailed explanation of this combustion process. Recently, more systematic approaches aiming at engine cold start optimization have been reported. For example, Laget et al [7] combined in-cylinder pressure analysis, endoscopic visualization and CFD modeling in order to identify the pre-glowing period, nozzle tip protrusion, injector spray angle and cranking speed as key parameters with influence on startability. Perrin et al [15] presented a more detailed analysis of the combustion sequence in which the location of the first ignition spots are shown to appear in the vicinity of the glow plug, together with the influence of some other parameters like swirl motion and rail pressure. Also, Chartier et al [16] showed how combustion starts close to the glow plug and does not spread to the whole chamber. All previous papers evidence the current interest of engine community to understand and optimize engine performance under cold start conditions. But most of them address the optimization of a particular engine or vehicle, studying the effect of specific engine parameters on cold start ease. Only few of them try to go deeper into an explanation about the physical mechanisms that control ignition and combustion.

In a previous work by the authors [17], a description of the mechanisms 
that lead to ignition under cold start conditions was presented as a basis to understand further parametric variations. The study was performed by means of visualization in a single-cylinder optical engine that was adapted to systematically reproduce in-cylinder conditions in a real engine at the beginning of the cold starting sequence. The importance of glow plug surface as the only possible ignition spot was confirmed, and it was shown that ignition occurred only after end of pilot injection. For this reason, transport processes that carry the fuel to the glow plug after end of injection were found to be remarkably important. These transport processes can be controlled indirectly by means of rail pressure and injection pulse duration. Furthermore, the injection event was shown to strongly influence combustion progression after ignition.

According to the previous results, it is worth investigating the role of nozzle geometry under cold start conditions, for which no dedicated studies have been found in the literature to date. The aim of the present paper is to show the effect that nozzle geometry has on the mechanisms that lead to ignition and control combustion to validate previous hypotheses and to establish basic criteria for nozzle design and engine optimization. The same experimental setup and methodology as in previous work [17] has been used. A more detailed explanation of the experimental approach can be found in [18]. As additional information for the subsequent analysis of nozzle influence on engine combustion, investigated nozzles have been characterized in terms of mass and momentum fluxes, and mixing evolution has been described by means of non-vaporizing spray visualization tests. After this introduction, the tools and methodology used for the study are presented. Next, the re- 
sults of nozzle characterization are shown. Later on, the influence of nozzle geometry on ignition and combustion are presented separately. Finally, the main outcomes of this work are summarized.

\section{Tools and methodology}

\subsection{Nozzle characterization tests}

To fully describe nozzle performance, two types of hydraulic characterization tests have been carried out: mass flow rate and spray momentum flux. Mass flow rate has been measured in a standard injection rate discharge curve indicator based on the Bosch method [19] (anechoic tub). These tests have been carried out following the same methodology used in [20, 21]. Spray momentum flux has been measured in a pressurized chamber filled with nitrogen, at the same pressure as in the optical engine at SOI. In this test rig, the nozzle is located within this chamber so that one of the sprays impacts on a piezo-electric pressure sensor that has been calibrated to measure force. In this way, the momentum induced by one spray during the stabilized injection period can be measured (transients are not measured properly). To check repeatability, all orifices from the same nozzle have been tested, but only the average value is shown in this paper. A more detailed explanation of the momentum flux measurement test rig and the method principle is shown in references [20, 22].

\subsection{Non-vaporizing spray visualization}

Spray visualization tests were carried out in a constant-volume vessel (the same used in $[23,24])$ filled with nitrogen at room temperature and at the 
same density as in the optical engine at SOI. The injector is horizontally mounted and a PixelFly CCD color camera (12 bit - dynamic range) records images through the optical access which is opposite to the injector holder. The PixelFly camera has been used with full resolution of $1280 \times 1024$ and a flash lamp was used for illumination. For a single injection only one image can be acquired so the spray evolution was scanned by recording images during different injections in $50 \mu s$ intervals, starting at start of injection and finishing when the spray tip reached the limit of field of view. Five repetitions were recorded at each condition to account for injection dispersion. Images were digitally processed using a purpose-developed software which measures maximum spray penetration for each spray in each image. The average value for each time instant is used in this paper. Additional details of the imageprocessing software are available in reference [25].

\subsection{Combustion visualization}

\subsubsection{Experimental facility}

A 4 -valve and $0.55 l$ displacement single cylinder optical engine was used in this study (sketched in Figure 1). It is equipped with an elongated piston with a cylindrical bowl, with dimensions of $45 x 16 \mathrm{~mm}$ (diameter $x$ depth), which allows optical access to the combustion chamber through a sapphire window placed in its bottom. Below the piston bowl, an elliptical UV mirror is placed on the cylinder axis. In front of the mirror, the high-speed camera is positioned to record radiation that comes from the combustion chamber. 
The whole facility was adapted, as explained previously in [18], to reproduce the first injection cycle of the starting sequence of a passenger car engine at $-20^{\circ} \mathrm{C}$. Specifically, real engine speed and thermodynamic conditions at TDC (temperature and pressure) can be reproduced systematically. Compared ot a real transient cold start sequence, the facility makes it possible to perform dedicated studies in which in-cylinder conditions remain unchanged and the independent influence of other parameters can be assessed. Although some phenomena that could play a role on cold start combustion are not reproduced, such as fuel impingement on the extremely cold cylinder walls or the effect of fuel temperature during injection [24], this facility allows to study the combustion process of a glow plug assisted engine under very critical ignition conditions. As a result, several measurements at the same condition can be done to perform statistical analysis, which is specially important due to the high dispersion in the combustion process.

Regarding the reproduced engine conditions, low engine speed (250 rpm) has been achieved by modifying the electronics of the dynamometer. Peak incylinder temperature has been reached by reducing compression ratio (from $16: 1$ to $8: 1$ ) and controlling intake temperature at $30^{\circ} \mathrm{C}$. Compression ratio has been reduced by placing an aluminum piece (shown in Figure 1), with $42 \mathrm{~mm}$ in height and internal diameter slightly larger than the engine bore, between the cylinder head and the engine block. Peak in-cylinder pressure (27 bar) has been set by controlling intake pressure in a plenum chamber. Besides these conditions, coolant and oil temperatures are also set to $30^{\circ} \mathrm{C}$. A standard glow plug [26] (Figure 1) was used for the study. At the nominal configuration, the tip protrudes $3 \mathrm{~mm}$ into the combustion chamber 
from the cylinder head plane, it is located at $11.5 \mathrm{~mm}$ from the cylinder axis and it is operated at a constant voltage of $11 \mathrm{~V}$.

A common rail injection system with piezo-injectors was operated externally to ensure stable behavior, avoiding uncertainties associated to corrections made by the ECU. The injector is centered in the cylinder and vertically mounted as shown in Figure 1. In that way, spray orientation with respect to the glow plug can be modified by rotating the injector around its axis. For this study, one of the sprays has been oriented at $12^{\circ}$ from the glow plug in swirl direction (swirl ratio: 2.2). Under this configuration, the minimum distance between the glow plug surface and the spray has been estimated to be $2.3 \mathrm{~mm}$. Injection was performed at a reduced frequency (one injection every 40 cycles) to avoid engine temperature increase, speed instability in case of ignition and to reduce window fouling. Each test consists of 20 to 30 injection cycles recorded under the same engine conditions.

\subsubsection{In-cylinder pressure analysis}

The tool employed to perform combustion analysis is the one-zone model CALMEC, which is described in [27]. This diagnosis tool uses the measured in-cylinder pressure as main input. The first law of thermodynamic is applied between IVC and EVO considering the chamber as an open system because of blow-by and fuel injection. The ideal gas equation of state is used to calculate the mean gas temperature in the chamber. Along with these two basic equations, several sub-models are used to calculate instantaneous volume and heat transfer [28], among others. The model main result is the Rate of Heat Release (ROHR). But the temporal evolution of other parameters like the Heat Release Law (HRL, defined as the integral of ROHR and normalized 
with respect to its maximum) or the mean gas temperature can be calculated. Temporal resolution for these variables depends on the crank angle encoder configuration $(0.5 C A D)$. Global information on each cycle can be obtained, such as Indicated Mean Effective Pressure (IMEP) and Start of Combustion (SOC). SOC is defined as the crank angle position where the beginning of the strong rise in ROHR due to combustion is detected.

\subsubsection{Image acquisition and post-processing}

Images were recorded using a Photron Ultima APX high-speed camera. It is equipped with a 10-bit CMOS sensor and all images in the study were recorded at an acquisition frequency of $6000 \mathrm{fps}$ to a $512 x$ 512-pixel image size. The camera was coupled with a $135-400 \mathrm{~mm}$ focal length Helmut APO objective with a number 1 close up lens.

In order to simplify combustion analysis, time resolved parameters were obtained for every image sequence by means of post-processing. First, segmentation is performed for every single image by calculating a threshold value equal to the minimum digital level in the image (found in a zone without combustion radiation) plus $15 \%$ of the difference between the maximum and the minimum. This percentage was chosen as a compromise to eliminate light reflected on the liquid spray and on the chamber walls without losing much information from the combustion event. After segmentation, the digital levels of all pixels containing combustion radiation (with digital levels above the threshold) are added into a single parameter, namely Cummulative Intensity $\left(I_{\text {cumul }}\right)$. Figure 2 shows a typical time evolution of this parameter. Additionally pilot probability, Luminosity Delay (LD) and Integrated Luminosity (IL) are used to characterize pilot injection. Pilot probability 
is defined as the percentage of cycles that show any luminosity out of the whole sample of recorded cycles. As shown in Figure 2, IL is defined as the integral of the $I_{\text {cumul }}$ plot, and LD is the time period between SOI and the first luminosity detection.

[Figure 2 about here.]

\subsection{Conditions of the study}

Four different multi-orifice micro-sac injector nozzles were selected to carry out the present study and their nominal characteristics are summarized on Table 2. In general, these nozzles are representative of those employed on passenger car diesel engines nowadays. Bosch flow number values range from 250 to $450 \mathrm{cc}$, number of orifices from 6 to 9 and orifice diameters from 0.121 to $0.145 \mathrm{~mm}$. The differences in included angle can be considered negligible based on the way combustion starts and progresses under these conditions [17]. It has been observed that pilot injection ignites in the glow plug vicinity after end of injection, with a strong influence of flow motion during this period. For this reason, a small variation in glow plug to spray distance induced by differences in included angle (around $0.5 \mathrm{~mm}$ ) can be considered as negligible. Regarding combustion progression, main combustion develops mainly from pilot flame and due to the negligible influence of included angle on this pilot flame, no major effects are expected of this parameter on main combustion either.

[Table 2 about here.]

Fuel discharge characteristics for each one of the four nozzles were measured in terms of mass flow rate and momentum flux for both levels of rail 
pressure, 250 and 370 bar. Mass flow rate was measured for five different amounts of injected mass $(3,6,12,24$ and $44 \mathrm{mg})$ with a constant backpressure of 27 bar for all cases. Momentum flux was measured in all cases for a single and long injection pulse of $44 \mathrm{mg}$.

Non-vaporizing spray visualization tests were carried out to investigate spray evolution under two density values. The first one was the same as in the optical engine at TDC $\left(16 \mathrm{~kg} / \mathrm{m}^{3}\right)$, while the secon one was $40 \mathrm{~kg} / \mathrm{m}^{3}$, which is representative of more "conventional" diesel engine operating conditions. In these tests, long injection pulses of $44 \mathrm{mg}$ for each one of the four nozzles and at both levels of rail pressure were tested.

Finally, combustion visualization tests were performed in the optical engine. Basic engine conditions were kept unchanged: engine speed $250 \mathrm{rpm}$; intake air, oil and water temperature were kept fixed at $30^{\circ} \mathrm{C}$ and intake pressure was set to reach target peak compression pressure $(27$ bar $)$. With these engine settings in-cylinder temperature and density were estimated to be $345^{\circ} \mathrm{C}(618 \mathrm{~K})$ and $16 \mathrm{~kg} / \mathrm{m}^{3}$, which are typical of low temperature cold start cranking process. Two levels of rail pressure were tested, namely 250 and $370 \mathrm{bar}$. The former one is the lowest possible value for stable behavior at short injection pulses, while the latter one is a value close to the limit above which ignition can not be achieved (as shown in a previous work [17]). The injection strategy consists of two separated pulses, namely $6 \mathrm{mg}$ at $0 C A D$ and $24 \mathrm{mg}$ at $5 C A D$. 


\section{Nozzle characterization results}

\subsection{Mass flow rate and momentum flux tests results}

Based on flow characterization, this section intends to show how fuel is delivered during the transient period at the beginning of injection, which affects pilot ignition, and during the period when the mass flow rate is completely stabilized, which controls main combustion rate.

For the stabilized injection period, mass flow rate and momentum flux results are shown in Figures 3 and 4, respectively. In both figures, results for the four nozzles at both levels of rail pressure and for a long single injection of $44 \mathrm{mg}$ are presented. Figure 3 shows how the mass flow rate traces reach a maximum stabilized period according to the Bosch flow number values given in Table 2. Nozzles $N 3$ and $N 4$ reach the highest mass flow rate, followed closely by nozzle $N 2$. Nozzle $N 1$ is considerably different, this nozzle reaches a maximum mass flow rate value which is around the half of those reached by nozzles $N 3$ or $N 4$. As a consequence, the injection time is considerably longer for nozzle $N 1$, if the amount of injected mass is the same. Figure 4 shows the total stabilized momentum flux and the effective area per orifice calculated according to:

$$
A_{e f f}=\dot{m}_{0}^{2} \div\left(\dot{M}_{0} * \rho_{f}\right)
$$

where $\rho_{f}$ is the fuel density, $\dot{m}_{0}$ and $\dot{M}_{0}$ are the mass flow rate and momentum flux per orifice, respectively, during the stabilized period. The total stabilized momentum flux (number of orifices times $\dot{M}_{0}$ ) is an important parameter which promotes mixing during main combustion. $A_{\text {eff }}$ values in Figure 4 agree with nominal area values calculated with nominal diameters from Table 
2 , and they will be used to estimate fuel velocity during the transient injection period.

[Figure 3 about here.]

[Figure 4 about here.]

For the transient injection period, Figure 5 shows the mass flow rate per orifice for a single pilot injection pulse of $6 \mathrm{mg}$, for the four nozzles and at both levels of rail pressure. Mass flow rate per orifice is selected, since pilot ignition is the result of the interaction between the glow plug and only one of the sprays. It must be taken into account that the amount of fuel injected per orifice is different among nozzles depending the number of holes, since the injection strategy maintains a constant total injected mass. From the results in Figure 5 it is clear that the mass flow rate traces never reach stabilization under these conditions and pilot injection is a completely transient event. Differences in mass flow rate among nozzles are smaller in comparison with differences in total mass flow rate under stabilised conditions (Figure 3).

[Figure 5 about here.]

Reliable momentum flux measurements during transients are not possible. Therefore, in order to characterize pilot injection, maximum fuel speed for these short pulses has been estimated. This parameter will be used as an indicator for the intensity of the fuel velocity after EOI and, which has been shown to have a strong influence on pilot ignition [17]. Effective injection speed $\left(U_{\text {eff }}\right)$ has been calculated according to Equation 2: 


$$
U_{e f f}=\dot{m}_{0} \div\left(A_{e f f} * \rho_{f}\right)
$$

where $\dot{m}_{0}$ is the measured mass flow rate per orifice (Figure 5), $\rho_{f}$ is the fuel density and $A_{e f f}$ is the effective nozzle area. The latter parameter is assumed to be constant and equal to the area calculated during the stabilized period (Figure 4). From the time evolution of the injection velocity, the maximum value is used as a characteristic parameter. A similar approach has been followed in [29] and it is considered quite acceptable for micro-sac nozzles. The estimated maximum fuel speed is plotted in Figure 6 for the four nozzles at both levels of rail pressure for a single injection of $6 \mathrm{mg}$. The maximum speed reached by nozzle $N 1$ is clearly higher than that by any of the other three nozzles. Nevertheless, a direct comparison must be done only with nozzle $N 2$, with the same amount of injected fuel per orifice. The difference between both nozzles could be due to the fact that the transient period at start of injection is faster for $N 1$, and therefore injection rate is closer to stabilization for this nozzle. Maximum fuel speed values for nozzles $N 2, N 3$ and N4 are very similar. But it must be noted that differences in fuel speed are due not only to the specific geometry of each nozzle, but also to a different amount of injected mass per orifice.

[Figure 6 about here.]

\subsection{Non-vaporizing spray visualization results}

Injections were performed into a volume filled with nitrogen at the same density as in the engine at TDC $\left(16 \mathrm{~kg} / \mathrm{m}^{3}\right)$ and at a higher density $\left(40 \mathrm{~kg} / \mathrm{m}^{3}\right)$ 
representative of "conventional" diesel engine operating conditions. Long injection pulses are used to identify spray penetration, although this information can also be used to analyze short pulses, at least until EOI. A representative example of the results is shown in Figure 7. For clarity, only two nozzles with different orifice diameter are shown (N2 and N4), at the high level of rail pressure and for both density values. Spray penetration is plotted against time, and mass flow rates are also shown as a reference of the injection event. For the low density case, spray penetrates linearly (with respect to time) reaching the bowl walls distance within a very short time. No differences between nozzles have been detected in spite of having very different orifice diameters. This lack of dependence can be better understood by looking at the high density case, for which two periods can be differentiated. From SOI until approximately $800 \mu s$, the spray penetrates quasi-linearly with no differences between nozzles, as in the low density case. But after that, penetration evolution proceeds at a slower rate (approximately with the square root of time). Differences start to arise and spray penetration is notably higher for nozzle $N 2$ in this second period. In fact, this is the logical trend since $N 2$ has the largest orifice diameter as reported previously by Naber and Siebers [30]. The duration of the first period corresponds approximately to the time for injection rate stabilization, and is similar for both ambient densities, as the injection rate is approximately the same. However, the spray reaches the field of view limit at the end of the first period in the low density case. For this reason, it is not possible to analyze trends after that point. Anyway, the bowl wall distance has been reached much earlier in the injection process, and therefore no differences can be expected during 
engine tests in free spray evolution. It can be concluded that, at low density conditions and with small combustion chambers (as in passenger car engines cold start), there is almost no difference in spray penetration for nozzles investigated. This means that the time for the spray to reach the glow plug or the bowl walls is practically the same for all nozzles.

[Figure 7 about here.]

\section{Nozzle influence on pilot ignition}

Previous work by the authors [17] has shown that pilot ignition can only be monitored by means of visualization, since the effect of pilot combustion on the ROHR trace is on the noise level. Experimental results have shown that ignition of pilot injection occurs solely close to the glow plug, where high temperature ensures a reasonable ignition delay. Vaporization process is very slow, and only a small amount of fuel vapour reaches the glow plug during the injection event due to the low air temperature within the chamber. After end of injection, residual flow together with transient air entrainment create a peak in equivalence ratio close to the glow plug area, which is favorable for combustion initiation. This peak is higher at low rail pressure and for shorter injections.

This sub-section aims to shed some light the controlling mechanisms of pilot injection ignition. For analysis purposes, results from visualization of tests where a single pilot injection has been performed are grouped according to the amount of fuel injected. For all nozzles, a total mass of $6 \mathrm{mg}$ has been injected. According to differences in number of holes, nozzles N1 and N2 inject the same amount of fuel per orifice, while nozzles $N 2, N 3$ and $N 4$ will 
make it possible to study the effect of changing the amount of injected mass per orifice.

\subsection{Ignition at constant injected mass per orifice}

Pilot injection results are analyzed in this sub-section for nozzles $N 1$ and $N 2$ at a constant injected mass per orifice of $1 \mathrm{mg}$. These results are shown in Figure 8 in terms of pilot probability, LD and IL as a function of maximum fuel speed, since nozzle characterization results have shown that the main effect of nozzle geometry and rail pressure observed in the investigated nozzles is a change in the speed at which fuel is delivered. Specifically, the maximum value of this speed has been chosen as a reference one. Results evidence that pilot probability and IL depend on fuel speed. Actually, both pilot probability and IL are observed to drastically decrease when fuel speed is increased. Besides, LD does not seem to depend on fuel speed, while LD seems to correlate with EOI, since the time between EOI and the appearance of the first flame spots is very similar for these four different injection conditions.

[Figure 8 about here.]

The present results agree with previous trends reported in [17] for an single nozzle where an increase of rail pressure was shown to decrease both ignition probability and IL. Under those conditions, pilot mass was kept constant when changing rail pressure (i.e. higher fuel velocity). Present results hint at the fact that changing fuel velocity by modifying either rail pressure or nozzle geometry have similar consequences. It also reinforces the hypothesis shown in [17] that an increase in fuel velocity increases the 
amount of fuel that reaches the piston wall, reducing the equivalence ratio close to the glow plug.

\subsection{Influence of injected mass per orifice}

Pilot injection results are analyzed in this section for nozzles $N 2, N 3$ and $N 4$ at a constant total injected mass of $6 \mathrm{mg}$. Figure 9 shows pilot probability, LD and IL as a function of the injected mass per orifice at the high level of rail pressure. Increasing injected mass per orifice, under these conditions, has a positive effect on the appearance probability of the pilot flame and on flame intensity (IL). Regarding LD, no large variation is observed when increasing the injected mass per orifice. In agreement with previous sub-section, the time between EOI and the first appearance of flame seems to remain constant for these three nozzles. These results hint at the fact that increasing injected mass per orifice with similar maximum fuel speed improves conditions for ignition noticeably due to an increasing equivalence ratio in the glow plug vicinity.

[Figure 9 about here.]

Results showed in this section have allowed to isolate the positive effect of increasing the amount of injected mass per orifice and the negative effect of increasing the fuel speed during the injection event. These two effects are combined when the total pilot injection mass is increased keeping the injection nozzle and rail pressure the same, which has been previously reported in [17]. Under such conditions, it was shown that increasing the total pilot injected mass made autoignition more difficult, delayed the apparition of flame and diminished the amount of light radiated by burning fuel. The 
present results indicate that the negative effect of increasing fuel speed is more important than the positive effect of increasing the amount of injected mass per orifice, which must be taken into account when selecting injection strategies for real engine cold start.

\section{Nozzle influence on main combustion}

Figure 10 illustrates the main combustion development for a pilot + main injection strategy under cold start conditions. A combustion cycle of nozzle $N 1$ at low rail pressure has been selected as a representative example. Main combustion starts when the spray closest to the glow plug reaches the pilot flame. From here on, combustion progresses by burning the fuel injected by this spray and later on propagating to the adjacent sprays. As injection finishes, the visible flame stops propagating, indicating that injection is the main promoter of the combustion progress. This sequence shows that cold start combustion can be divided into two problems: ignition and main combustion progress. Ignition is promoted by pilot flame and controlled by parameters studied in the previous section. Combustion progress is controlled by the main injection event.

\section{[Figure 10 about here.]}

Figure 11 evidences the relationship between pilot flame and main combustion for the conditions investigated in the present paper. Combustion probability (IMEP higher than zero) of full injection tests is plotted versus flame appearance probability (IL higher than zero) measured in tests with the same pilot injection strategy but without the main pulse. It must be noted 
that full and pilot injection results stem from in-cylinder pressure analysis and flame visualization, respectively. Although the match is not completely perfect, the information given in this figure proves that pilot ignition clearly influences the full-strategy success for the conditions tested. The higher the pilot probability, the higher the main combustion probability. Additionally, the strong influence of rail pressure is also shown in this figure, as high pilot and main combustion probability are achieved at low rail pressure.

[Figure 11 about here.]

Regarding the fact that injection is the main combustion promoter, it was also reported in [17] that increasing rail pressure has a positive effect on IMEP, probably due to a higher momentum induced by the injection event that enhances mixing process. This statement can be confirmed from Figure 12, which shows IMEP as a function of the total stabilized momentum flux (Figure 4). Conditions correspond to full-strategy combustion tests for the four nozzles and both levels of rail pressure. IMEP is calculated from cycles with positive work out of a 30 repetition test. The plot somehow collapses results from the different nozzles. Increasing total momentum flux results in an increase in IMEP, which can be achieved by increasing momentum flux per orificie (i.e. by increasing injection pressure or nozzle diameter, nozzles $N 1$ and $N 2$ ) or by increasing the number of orifices. In both cases, the effect on IMEP is positive, most probably due to the intimate positive link between momentum flux and mixing and vaporization processes, which enhances combustion propagation. Consequently, high momentum values are desirable to improve combustion process under cold start conditions. 


\section{Summary and conclusions}

A study on the influence of injector nozzle geometry on ignition and combustion progress under cold start conditions has been presented. This study has been carried out in a specially adapted facility which allows to reproduce, repetitively and in a systematic manner, low speed and low temperature conditions such as those achieved by a passenger car diesel engine at $-20^{\circ} \mathrm{C}$. In this facility, classical in-cylinder pressure analysis can be coupled with highspeed visualization which has allowed more insight to be gained into the ignition and combustion progression controlling mechanisms.

For conditions under investigation, it has been shown how combustion initiation is promoted, almost exclusively, by pilot injection flame. This clear dependence allowed the combustion problem to be split in two parts: ignition and main combustion. Ignition is controlled by pilot injection and can only be monitored by means of visualization. Main combustion progress is promoted by the injection event, and can be monitored with classical incylinder pressure analysis, as well as with combustion visualization.

Two parameters have been shown to have a clear influence on pilot ignition: injected mass per orifice and speed. Increasing the amount of fuel injected per orifice at similar fuel speed, improves conditions for ignition probably by carrying a larger amount of fuel to the glow plug and increasing the local equivalence ratio. Increasing fuel speed reduces ignition probability considerably by carrying a larger amount of fuel towards the piston wall away from the glow plug. For this reason, conditions for pilot ignition are 
enhanced at low rail pressure and/or by using short injection pulses.

Regarding main combustion progress, a positive dependence has been found between momentum induced by the injection event and the amount of work obtained per cycle. For this reason, increasing rail pressure is desirable during main combustion. All in all, both single pilot and full injection results lead to the conclusion that a compromise must be made, at least under these conditions, to find optimum settings for both ignition and combustion progress.

\section{References}

[1] Yassine, M.K., Tagomori, M.K., Henein, N.A., Bryzik, W.. White smoke emissions under cold starting of diesel engines. SAE Paper 960249 1996;

[2] Peng, H., Cui, Y., Shi, L., Deng, K.. Effects of exhaust gas recirculation (egr) on combustion and emissions during cold start of direct injection (di) diesel engine. Energy 2008;33(3):471 - 479. doi: 10.1016/j.energy.2007.10.014.

[3] Peng, H.Y., Cui, Y., Deng, H.Y., Shi, L., Li, L.G.. Combustion and emissions of a direct-injection diesel engine during cold start under different exhaust valve closing timing conditions. Proceedings of the Institution of Mechanical Engineers, Part D: Journal of Automobile Engineering 2008;222(1):119-129.

[4] Weilenmann, M., Favez, J., Alvarez, R.. Cold-start emissions of modern passenger cars at different low ambient temperatures and their 
evolution over vehicle legislation categories. Atmospheric Environment 2009;43(15):2419-2429.

[5] Broatch, A., Ruiz, S., Margot, X., Gil, A.. Methodology to estimate the threshold in-cylinder temperature for self-ignition of fuel during cold start of diesel engines. Energy 2010;35:2251-2260.

[6] Pacaud, P., Perrin, H., Laget, O.. Cold start on diesel engine: Is low compression ratio compatible with cold start requirements? SAE Paper 2008-01-1310 2008;.

[7] Laget, O., Pacaud, P., Perrin, H.. Cold start on low compression ratio diesel engine: Experimental and 3D RANS computation investigations. Oil and Gas Science and Technology Rev IFP 2009;64(3):407-429.

[8] MacMillan, D., La Rocca, A., Shayler, P.J., Murphy, M., Pegg, I.G.. The effect of reducing compression ratio on the work output and heat release characteristics of a DI diesel under cold start conditions. SAE Paper 2008-01-1306 2008;.

[9] Johnson, T.V.. Review of $\mathrm{CO}_{2}$ emissions and technologies in the road transportation sector. SAE paper 2010;2010-01-1276. doi:10.4271/201001-1276. URL http://papers.sae.org/2010-01-1276.

[10] Johnson, T.V.. Review of diesel emissions and control. SAE paper 2010;2010-01-0301. doi:10.4271/2010-01-0301. URL http://papers.sae.org/2010-01-0301.

[11] Payri, F., Broatch, A., Serrano, J.R., Rodríguez, L.F., Esmorís, 
A.. Study of the potential of intake air heating in automotive DI diesel engines. SAE Paper 2006-01-1233 2006;

[12] Henein, N.A., Zahdeh, A.R., Yassine, M.K., Bryzik, W.. Diesel engine cold starting: combustion instability. SAE Paper 920005 1992;.

[13] Zahdeh, A.R., Henein, N.A., Bryzik, W.. Diesel cold starting actual cycle analysis under border-line conditions. SAE Paper 900441 1990;.

[14] Osuka, I., Nishimura, M., Tanaka, Y., Miyaki, M.. Benefits of new fuel injection system technology on cold startability of diesel engines improvements on cold startability and white smoke reduction by means of multi injection with common rail fuel system (ECD-U2). SAE Paper 940586 1994;

[15] Perrin, H., Dumas, J.P., Laget, O., Walter, B.. Analysis of combustion process in cold operation with a low compression ratio diesel engine. SAE Paper 2010-01-1267 2010;.

[16] Chartier, C., Aronsson, U., Andersson, Ö., Egnell, R.. Effect of injection strategy on cold start performance in an optical light-duty DI diesel engine. SAE Paper 2009-24-0045 2009;.

[17] Pastor, J.V., García-Oliver, J.M., Pastor, J.M., Ramírez-Hernández, J.G.. Ignition and combustion development for high speed direct injection diesel engines under low temperature cold start conditions. Fuel 2011;90(4):1556 - 1566 .

[18] Pastor, J.V., García-Oliver, J.M., Pastor, J.M., Ramírez-Hernández, J.G.. Experimental facility and methodology for systematic studies of 
cold startability in direct injection diesel engines. Meas Sci Technol 2009;20(095109). doi:10.1088/0957-0233/20/9/095109.

[19] Bosch, W.. The fuel rate indicator: a new measuring instrument for display of the characteristics of individual injection. SAE Paper 660749 1966 ;

[20] Payri, R., García, J.M., Salvador, F., Gimeno, J.. Using spray momentum flux measurements to understand the influence of diesel nozzle geometry on spray characteristics. Fuel 2005;84:551-561.

[21] Payri, R., Salvador, F.J., Gimeno, J., Bracho, G.. A new methodology for correcting the signal cumulative phenomenon on injection rate measurements. Experimental techniques 2008;31(1):46-9.

[22] Payri, R., Salvador, F., Gimeno, J., Zapata, L.. Diesel nozzle geometry influence on spray liquid-phase fuel penetration in evaporative conditions. Fuel 2008;87:1165-1176.

[23] Pastor, J., Payri, R., López, J.J., Julia, J.E.. Effect of injector nozzle geometry of diesel engines on the macroscopic spray characteristics by means of optical techniques. In: In Transactions 2003-2 of IMechE Two Day Conference on Fuel Injection Systems. Professional Engineering Publishing, London; 2002, p. 73-82.

[24] Payri, R., Salvador, F., Gimeno, J., Bracho, G.. Effect of fuel properties on diesel spray development in extreme cold conditions. Proceedings of the Institution of Mechanical Engineers, Part D: Journal of Automobile Engineering 2008;222(9):1743-1753. 
[25] Pastor, J., Arrégle, J., García, J., Zapata, L.. Segmentation of diesel spray images with log-likelihood ratio test algorithm for non-gaussian distributions. Appl Optics 2007;46(6):888-889.

[26] Lindl, B., Schmitz, H.. Cold-start equipment for diesel direct-injection engines. SAE Paper 1999-01-1244 1999;.

[27] Payri, F., Molina, S., Martín, J., Armas, O.. Influence of measurement errors and estimated parameters on combustion diagnosis. Applied Thermal Engineering 2006;(26):226 - 236.

[28] Torregrosa, A., Olmeda, P., Degraeuwe, B., Reyes, M.. A concise wall temperature model for di diesel engines. Applied Thermal Engineering 2006;(26):1320 - 1327.

[29] Payri, R., Salvador, F.J., Gimeno, J., De la Morena, J.. Influence of injector technology on injection and combustion development part 1: Hydraulic characterization. Applied Energy 2011;88(4):1068-74.

[30] Naber, J.D., Siebers, D.L.. Effects of gas density and vaporization on penetration and dispersion of diesel sprays. SAE Paper 960034 1996; 


\section{List of Figures}

1 Sketch of the optical access in the single cylinder engine and an image showing how the combustion chamber is imaged from the camera. 1.- Glow plug, 2.- Injector nozzle, 3.- Pressure transducer, 4.- Aluminum piece, 5.- Sapphire window, 6.Elongated piston, 7.- Elliptical UV mirror. . . . . . . . . .

$2 \quad I_{\text {cumul }}$ as a function of time for a pilot injection test. LD is defined as the time from SOI to flame appearance. IL is defined as the area under the $I_{\text {cumul }}$ trace. . . . . . . . . . 30

3 Fuel mass flow rate as a function of time for each of the nozzles tested with a single injection strategy of $44 \mathrm{mg}$ at both levels of rail pressure. . . . . . . . . . . . . . . 31

4 Total stabilized momentum flux (measured momentum flux times the number of orifices) and $A_{\text {eff }}$ at both levels of rail pressure for the four nozzles. . . . . . . . . . . . . 32

5 Mass flow rate per orifice as a function of time ASOE for the four nozzles tested at both levels of rail pressure. . . . . . . . 33

$6 \quad$ Estimated maximum fuel speed reached during pilot injection for the four nozzles, at both levels of rail pressure and for single injection of $6 \mathrm{mg} . \ldots \ldots . \ldots . \ldots 34$

$7 \quad$ Spray penetration as a function of time for nozzles 2 and 4 at the high level of rail pressure for two different densities, $16 \mathrm{~kg} / \mathrm{m}^{3}$ (left) and $40 \mathrm{~kg} / \mathrm{m}^{3}$ (right). Mass flow rate for a long and a pilot injection are plotted at the top of each graph. Additionally, the limit of the field of view and the bowl wall distance are indicated with dashed lines. . . . . . . . . .

8 Pilot probability (top), LD (middle) and IL (bottom) as a function of maximum fuel speed at both levels of rail pressure, for nozzles $N 1$ and $N 2$ with a constant injection strategy of $6 \mathrm{mg}$ at TDC. On the LD graph, a line representing EOI is plotted as a reference of the injection event. . . . . . . . . 36

9 Pilot probability (top), LD (middle) and IL (bottom) as a function of injected mass per orifice. These results correspond to a rail pressure of $370 \mathrm{bar}$, for a single injection pulse of $6 \mathrm{mg}$ for the nozzles $N 2, N 3$ and $N 4$. On the LD graph, a line representing EOI is plotted as a reference of the injection event. 
10 Injection pulse, ROHR and $I_{\text {cumul }}$ as a function of the crank angle position together with selected images of a combustion cycle at the low level of rail pressure for nozzle $N 1$, pilot injection of $6 \mathrm{mg}$ injected at $0 C A D$ and main pulse of $24 \mathrm{mg}$ at $5 C A D$. Radial lines on the top left image correspond to the approximate locations of the sprays. . . . . . . . . 38

11 Combustion probability (IMEP higher than zero) for full injection tests as a function of the pilot flame probability (IL higher than zero) for the four nozzles and both levels of rail pressure. . . . . . . . . . . . . . . . 39

12 Average IMEP for cycles with positive work of 30 repetitions tests as a function of the momentum multiplied by the number of orifices. The confidence interval of the mean (with a confidence level of 95\%) is plotted with error bars. Both levels of rail pressure are plotted for the four nozzles. . . . . . . . . . . 40 

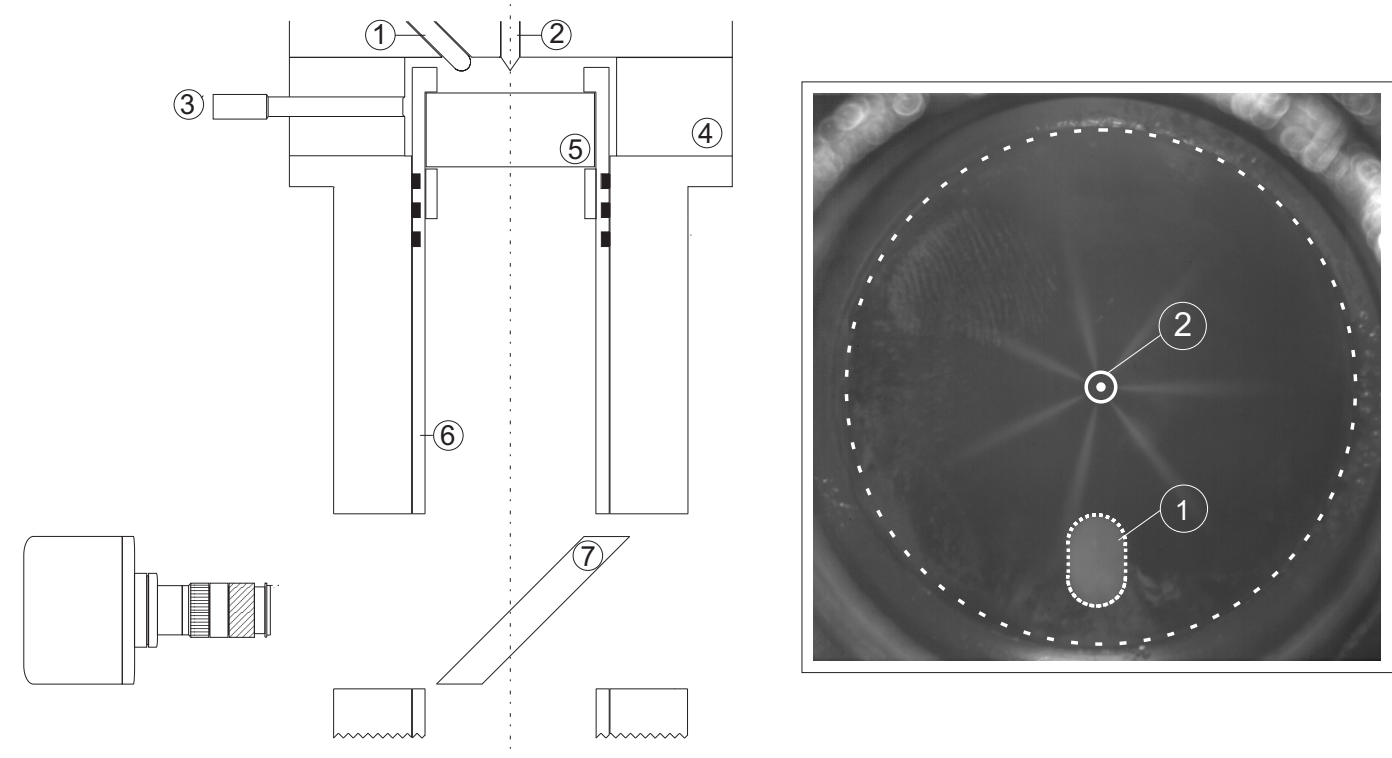

Figure 1: Sketch of the optical access in the single cylinder engine and an image showing how the combustion chamber is imaged from the camera. 1.- Glow plug, 2.- Injector nozzle, 3.- Pressure transducer, 4.- Aluminum piece, 5.- Sapphire window, 6.- Elongated piston, 7.- Elliptical UV mirror. 


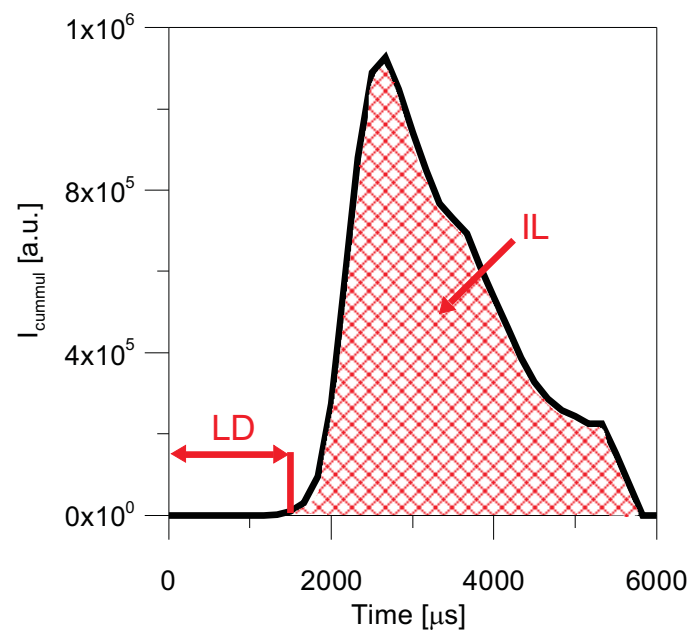

Figure 2: $I_{\text {cumul }}$ as a function of time for a pilot injection test. LD is defined as the time from SOI to flame appearance. IL is defined as the area under the $I_{\text {cumul }}$ trace. 

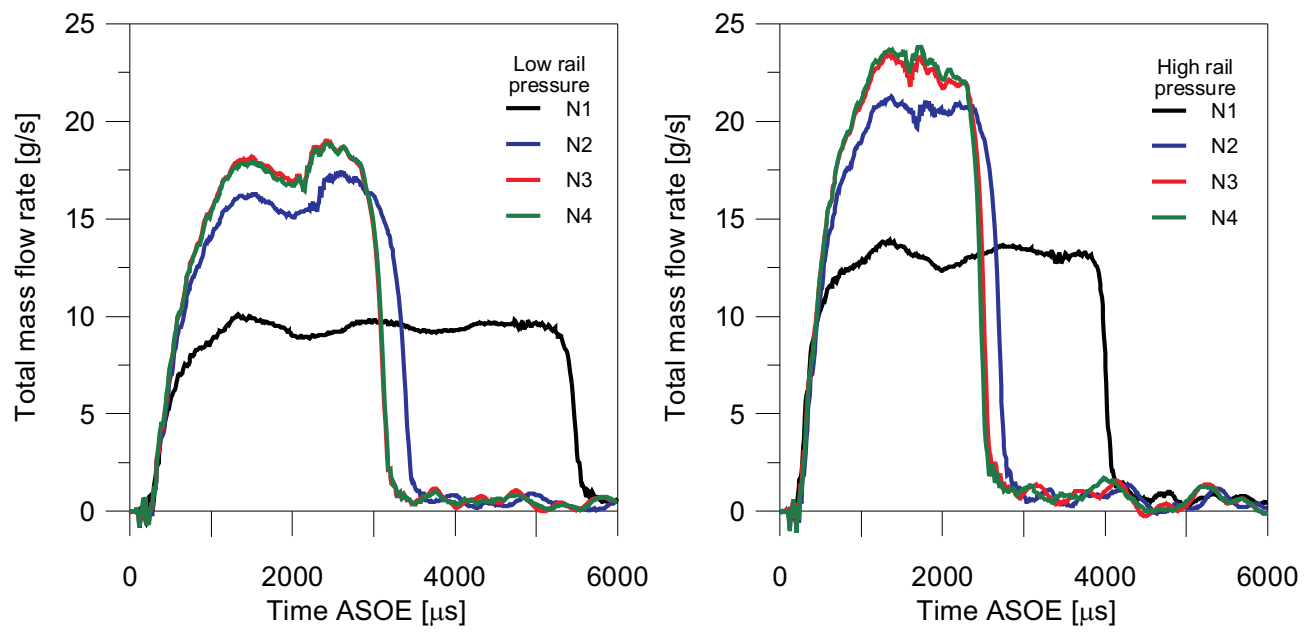

Figure 3: Fuel mass flow rate as a function of time for each of the nozzles tested with a single injection strategy of $44 \mathrm{mg}$ at both levels of rail pressure. 

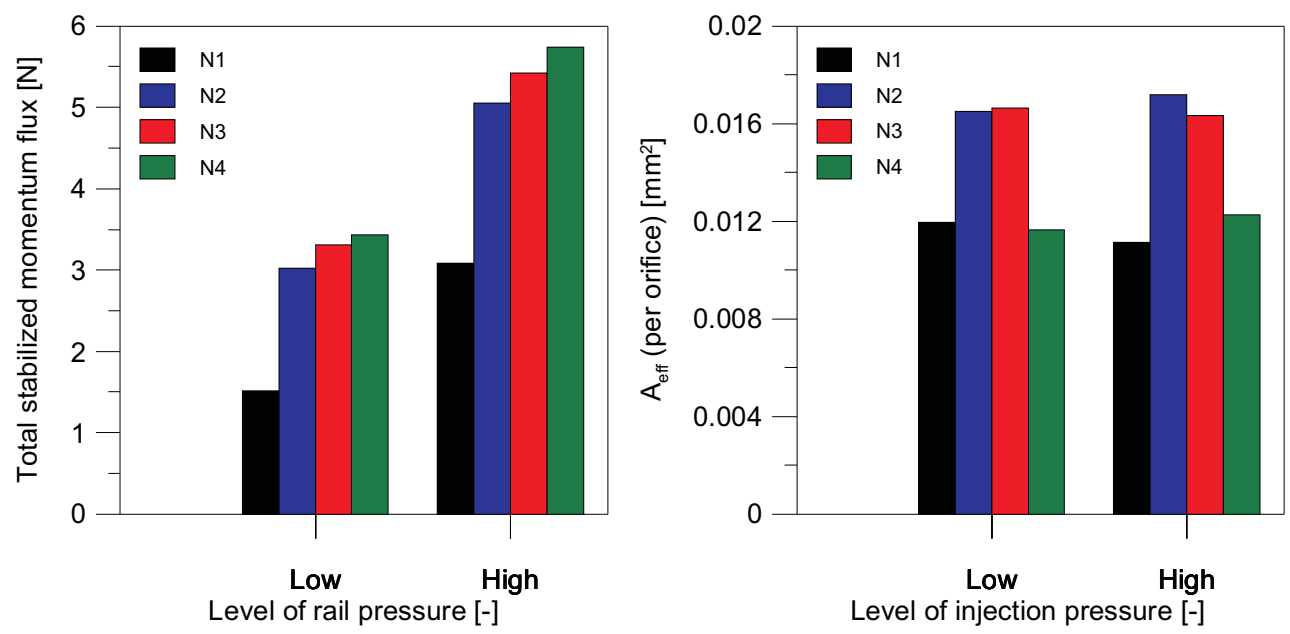

Figure 4: Total stabilized momentum flux (measured momentum flux times the number of orifices) and $A_{e f f}$ at both levels of rail pressure for the four nozzles. 

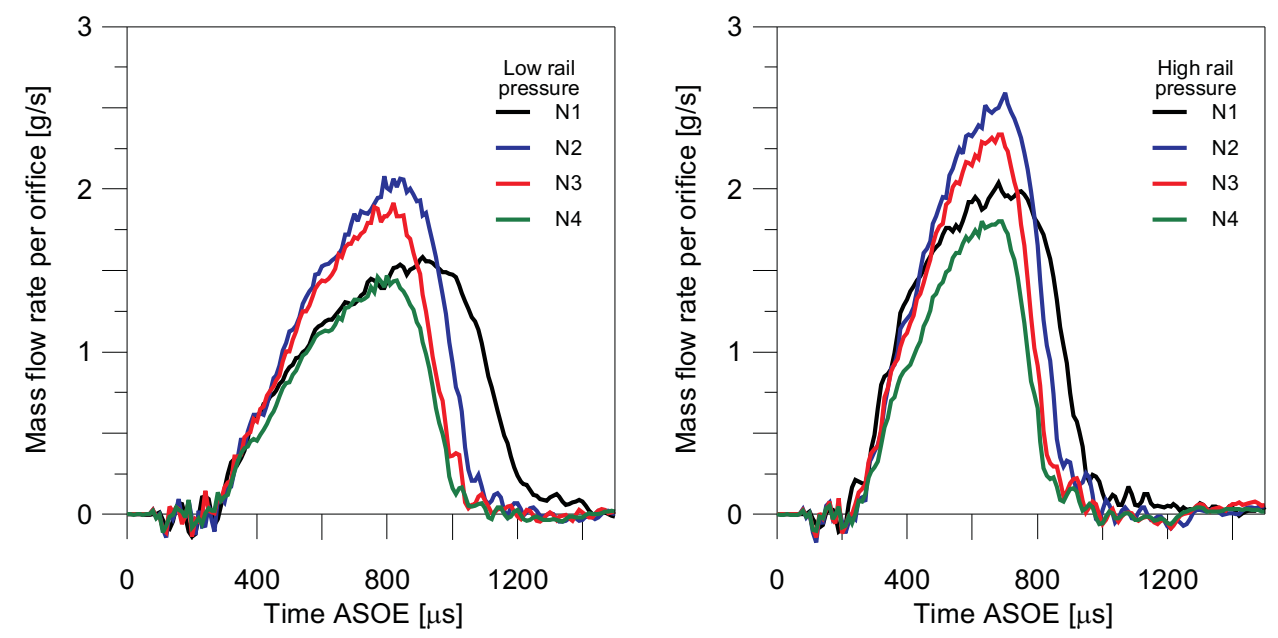

Figure 5: Mass flow rate per orifice as a function of time ASOE for the four nozzles tested at both levels of rail pressure. 


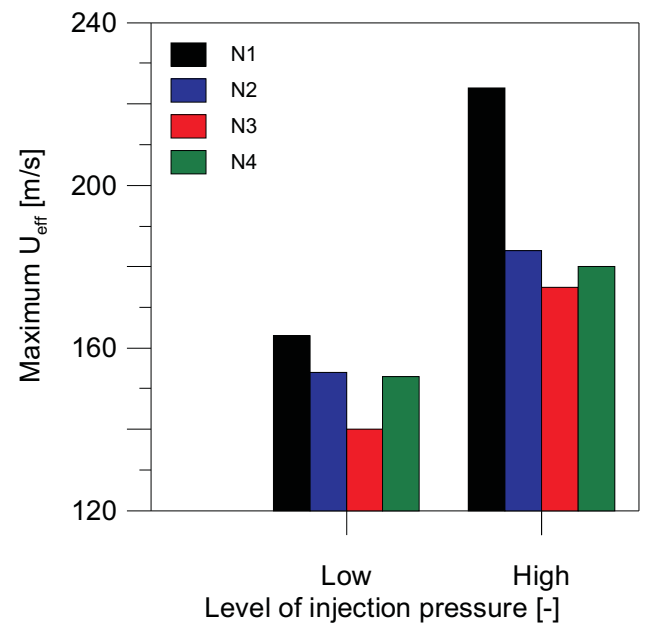

Figure 6: Estimated maximum fuel speed reached during pilot injection for the four nozzles, at both levels of rail pressure and for single injection of $6 \mathrm{mg}$. 

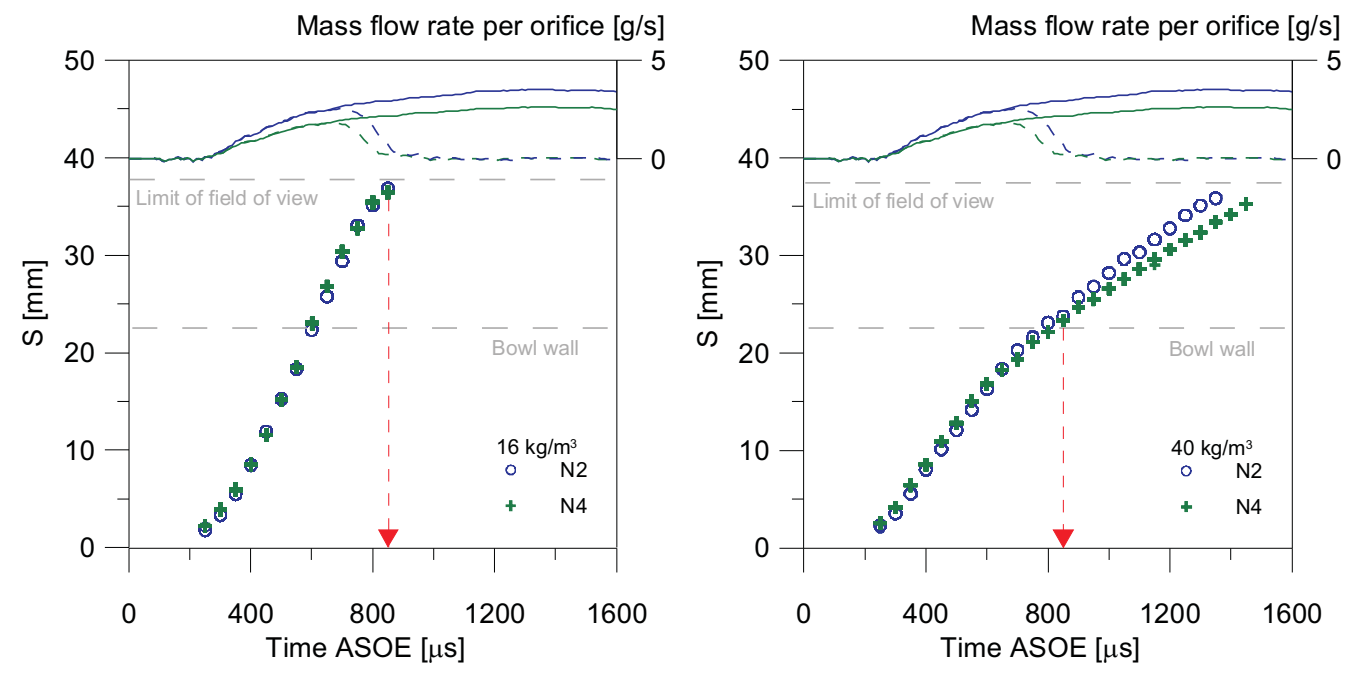

Figure 7: Spray penetration as a function of time for nozzles 2 and 4 at the high level of rail pressure for two different densities, $16 \mathrm{~kg} / \mathrm{m}^{3}$ (left) and $40 \mathrm{~kg} / \mathrm{m}^{3}$ (right). Mass flow rate for a long and a pilot injection are plotted at the top of each graph. Additionally, the limit of the field of view and the bowl wall distance are indicated with dashed lines. 

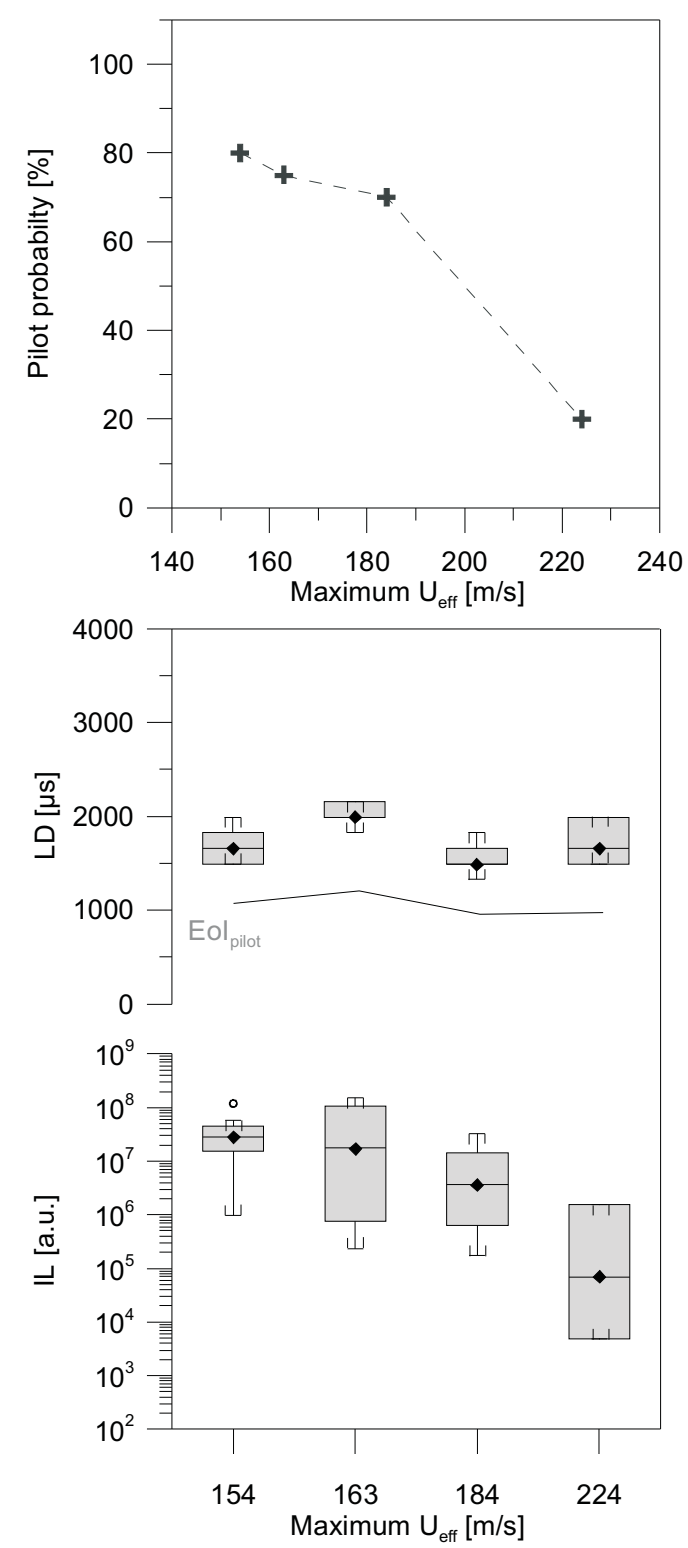

Figure 8: Pilot probability (top), LD (middle) and IL (bottom) as a function of maximum fuel speed at both levels of rail pressure, for nozzles $N 1$ and $N 2$ with a constant injection strategy of $6 \mathrm{mg}$ at TDC. On the LD graph, a line representing EOI is plotted as a reference of the injection event. 

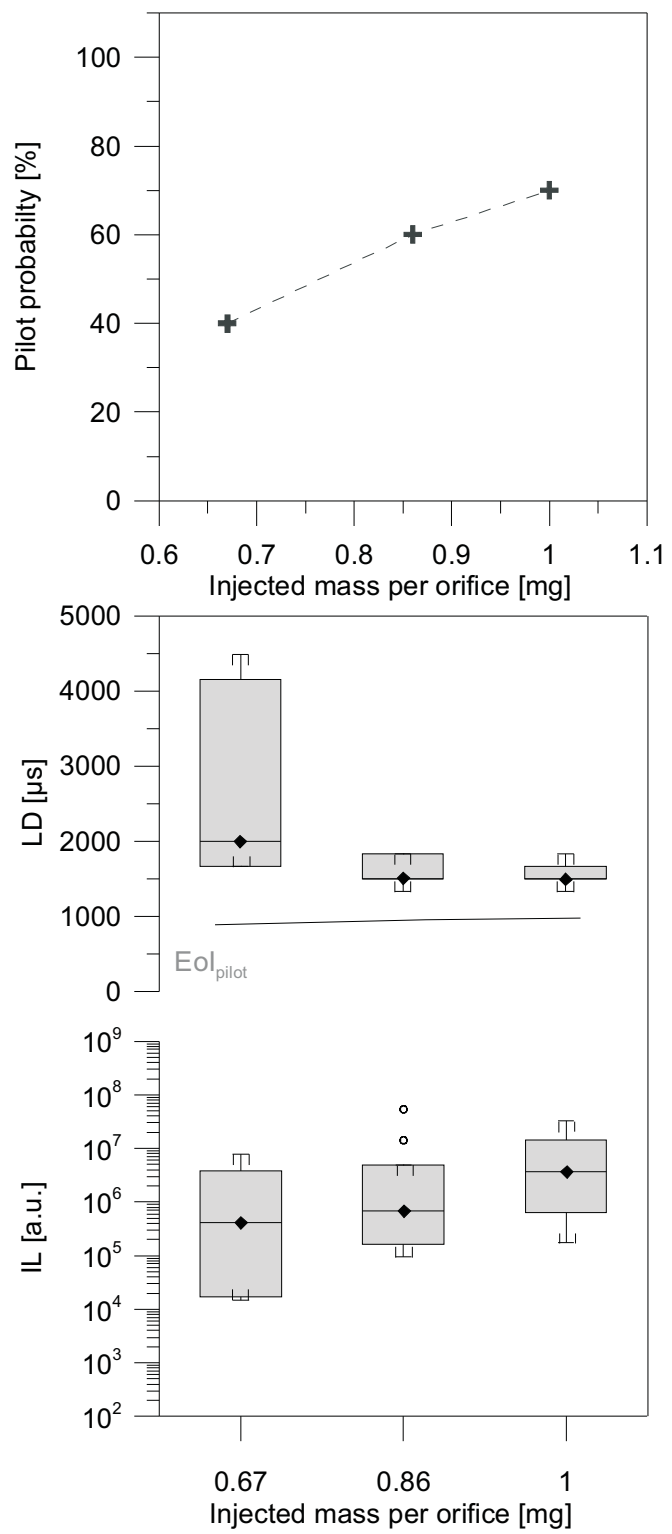

Figure 9: Pilot probability (top), LD (middle) and IL (bottom) as a function of injected mass per orifice. These results correspond to a rail pressure of $370 \mathrm{bar}$, for a single injection pulse of $6 \mathrm{mg}$ for the nozzles $N 2, N 3$ and $N 4$. On the LD graph, a line representing EOI is plotted as a reference of the injection event. 


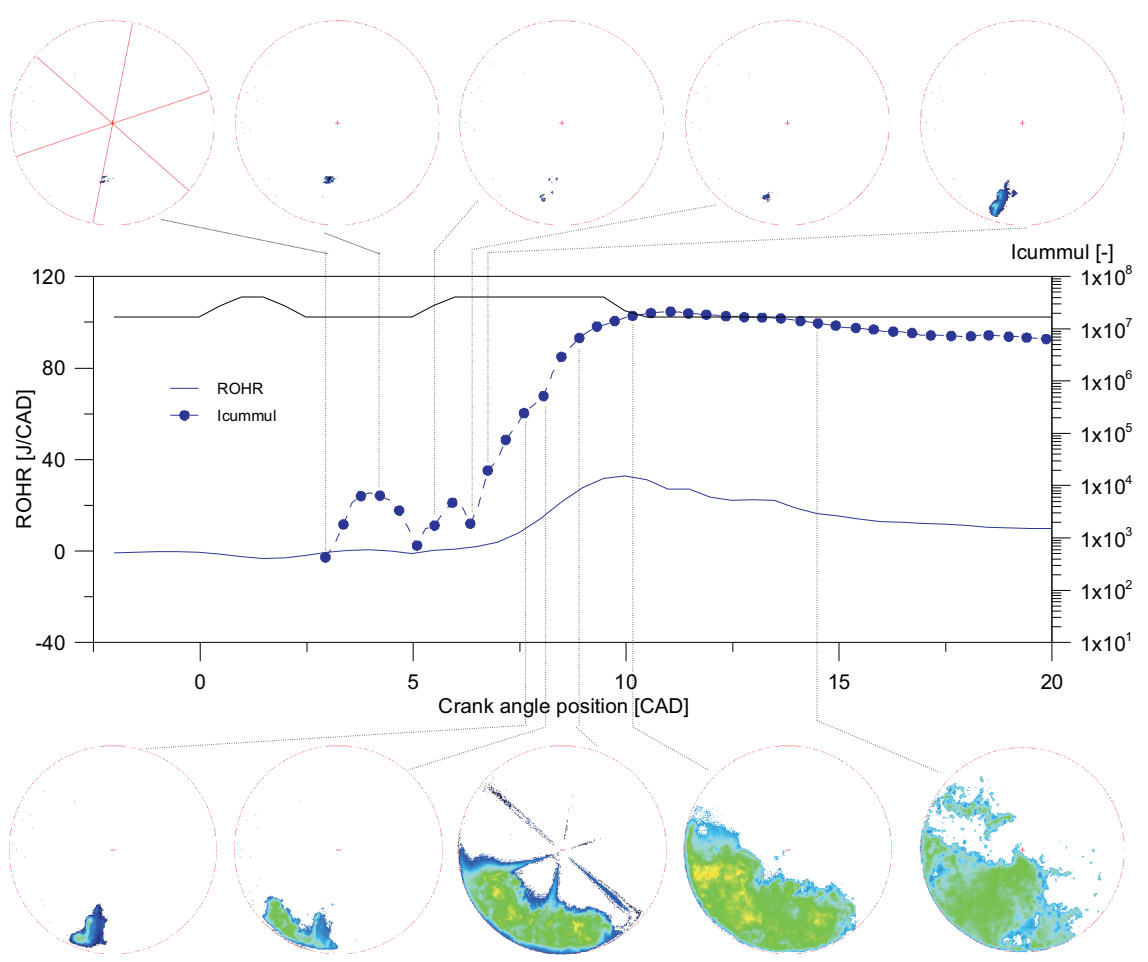

Figure 10: Injection pulse, ROHR and $I_{\text {cumul }}$ as a function of the crank angle position together with selected images of a combustion cycle at the low level of rail pressure for nozzle $N 1$, pilot injection of $6 \mathrm{mg}$ injected at $0 C A D$ and main pulse of $24 \mathrm{mg}$ at $5 C A D$. Radial lines on the top left image correspond to the approximate locations of the sprays. 


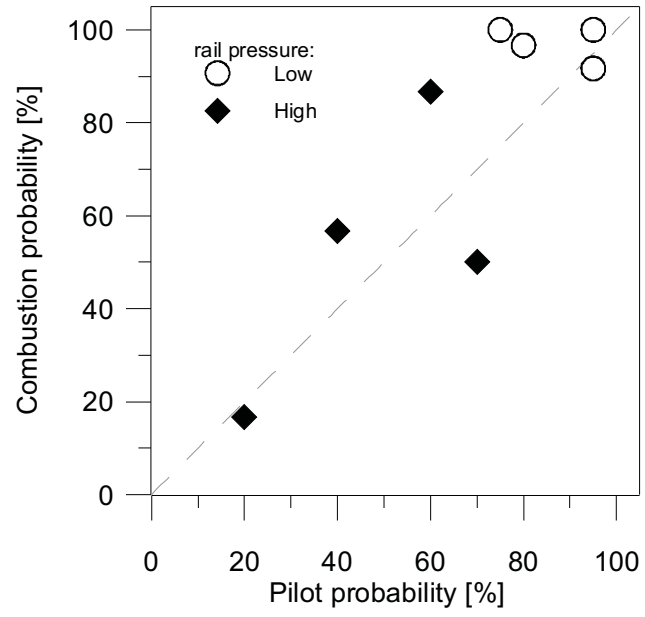

Figure 11: Combustion probability (IMEP higher than zero) for full injection tests as a function of the pilot flame probability (IL higher than zero) for the four nozzles and both levels of rail pressure. 


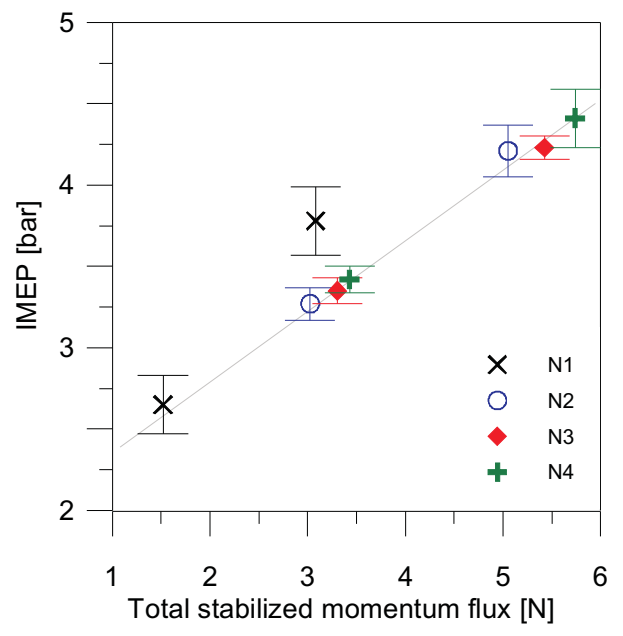

Figure 12: Average IMEP for cycles with positive work of 30 repetitions tests as a function of the momentum multiplied by the number of orifices. The confidence interval of the mean (with a confidence level of $95 \%$ ) is plotted with error bars. Both levels of rail pressure are plotted for the four nozzles. 


\section{List of Tables}

1 Abbreviations .................... . . 42

2 Nominal characteristics of the four multi-orifice injection nozzles selected for the study. . . . . . . . . . . . . . . . 43 
Table 1: Abbreviations

\begin{tabular}{|c|c|c|c|}
\hline Nomenc & clature & $\mathrm{CCD}$ & charge-coupled device \\
\hline A & area, $m^{2}$ & CFD & computational fluid dynamics \\
\hline & light intensity, - & CMOS & complementary metal oxide semiconductor \\
\hline & mass flow, $\mathrm{kg} / \mathrm{s}$ & $\mathrm{ECU}$ & engine control unit \\
\hline$\dot{M}$ & Momentum flux, $N$ & EOI & end of injection \\
\hline $\mathrm{S}$ & spray penetration, $\mathrm{mm}$ & EVO & exhaust valve opening \\
\hline & speed, $\mathrm{m} / \mathrm{s}$ & HRL & heat release law \\
\hline Subscript & & & integrated luminosity \\
\hline & conditions at nozzle exit & IMEP & indicated mean effective pressure \\
\hline $\begin{array}{l}\text { cummul } \\
\text { eff }\end{array}$ & accumulated & IVC & intake valve closing \\
\hline & fuel & ROHR & rate of heat release \\
\hline Greek syr & mbols & SOC & start of combustion \\
\hline$\rho$ Abbreviat & density & SOE & start of energizing \\
\hline ASOE & after start of energizing & TDC & $\begin{array}{l}\text { start of injection } \\
\text { top dead centre }\end{array}$ \\
\hline CAD & crank angle degree & & ultraviolet \\
\hline
\end{tabular}


Table 2: Nominal characteristics of the four multi-orifice injection nozzles selected for the study.

\begin{tabular}{|l|c|c|c|c|}
\hline Nozzle & N1 & N2 & N3 & N4 \\
\hline Number of orifices [-] & 6 & 6 & 7 & 9 \\
\hline Bosch flow number [cc/30s 100bar] & 250 & 400 & 450 & 450 \\
\hline included angle[deg] & 155 & 150 & 153 & 153 \\
\hline Diameter [mm] & 0.121 & 0.145 & 0.142 & 0.125 \\
\hline K-factor [-] & 0 & 1.5 & 1.5 & 1.5 \\
\hline
\end{tabular}

